\title{
The presence of abnormal lysosomes in lymphocytes and neutrophils during chloroquine therapy: a quantitative ultrastructural study
}

\author{
CAROLYN J.P. JONES, RICHARD S. SALISBURY, AND \\ MALCOLM I. V. JAYSON
}

From the Rheumatic Diseases Centre, University of Manchester, Hope Hospital, Salford M6 8HD.

SUMMARY Lysosomal ultrastructure in circulating lymphocytes and neutrophils from the blood of 22 patients with rheumatoid arthritis or systemic lupus erythematosus undergoing chloroquine therapy has been examined and compared with that of rheumatoid cases receiving alternative forms of treatment and non-rheumatoid controls. The lymphocytes of all 22 patients receiving chloroquine showed a highly significant number of lamellar inclusion bodies (mean $9 \cdot 3 \%$ ) compared with only occasional inclusions in six of the 14 rheumatoid and four of the 12 non-rheumatoid controls (means $0.86 \%$ and $0.83 \%$ respectively). Neutrophils from eight chloroquine-treated patients also showed abnormal granules which were absent from both control groups. These findings confirm our earlier in vitro work which indicated that lymphocytes, compared with neutrophils, had a greater susceptibility to chloroquine action with respect to alterations in lysosomal structure.

Key-words: anti-inflammatory agents, antimalarials, leucocytes, lupus erythematosus (systemic), rheumatology.

We have recently demonstrated ${ }^{1}$ that exposure of normal human circulating leucocytes to therapeutic concentrations of chloroquine $(5-0.05 \mu \mathrm{g} / \mathrm{ml})$ for four hours in vitro produces a significant increase in the number of autophagosomes in lymphocytes, while neutrophils appear to be unaffected by the drug. To establish whether this finding occurs in vivo during chloroquine therapy we have undertaken a study of lysosomal ultrastructure in circulating leucocytes from patients with rheumatoid arthritis and systemic lupus erythematosus receiving chloroquine for periods ranging from two days to 20 months.

\section{Materials and methods}

Three groups of subjects were examined: (1) Chloroquine treated group: 22 patients receiving chloro-

Accepted for publication 3 April 1984.

Correspondence to Dr C. J. P. Jones, Department of Pathology, University of Manchester, Manchester M13 9PT. quine phosphate or hydroxychloroquine either alone or in combination with other drugs for rheumatoid arthritis (18) or systemic lupus erythematosus (4). (2) Rheumatoid control group: 14 patients with definite rheumatoid arthritis (ARA classification) being treated with non-steroidal antiinflammatory drugs, analgesics, or untreated (1). (3) Normal control group: 9 normal healthy volunteers and 3 patients with heart disease, untreated with analgesics or anti-inflammatory drugs.

Between 5 and $10 \mathrm{ml}$ of venous blood was withdrawn from each case into a tube containing lithium heparin beads, and $\mathbf{0 . 2 5} \mathrm{ml}$. Dextraven 150 (Fisons) (6\% dextran 150 in solution) was added per millilitre of blood. After gentle mixing, the tubes were left in an inclined position at $37^{\circ} \mathrm{C}$ for one hour, and the leucocyte-rich supernatant carefully removed with a siliconised pipette. Centrifugation at $1200 \mathrm{rpm}$ for 8 minutes was followed by resuspension of the cells in $2 \mathrm{ml}$ Dulbecco's phosphatebuffered saline (with added magnesium and cal- 
cium), which was left at $37^{\circ} \mathrm{C}$ for 15 minutes in order to allow the leucocytes to recover their normal form. Fixation and subsequent processing was carried out as previously described, ${ }^{2}$ and, after double staining with uranyl acetate and lead citrate, sections were examined in either a Philips 301 or an AEI EM6B electron microscope.

\section{QUANTIFICATION}

Specimens were coded and examined 'blind'. One hundred lymphocytes and 200 neutrophils were counted from each case. The number of cells containing abnormal lysosomal granules and the number of abnormal granules per cell were recorded. In the case of neutrophils only those granules showing a distinctive lamellar structure were noted. This was felt to be necessary as many cells contained slightly abnormal, swollen granules, and it was considered to be important not to confuse these with the very characteristic granule produced by the action of chloroquine. Occasional myelin bodies were seen which superficially resembled chloroquine granules but with a much looser, more open structure. These never exceeded one per cell and were recorded separately.

\section{Results}

\section{LYMPHOCYTES}

Blood from all 22 patients receiving chloroquine contained lymphocytes exhibiting bizarre inclusions which were composed of concentric, electron-dense lamellae (Table 1). Although only one was generally found per cell, some contained up to six inclusions. often clustered together (Fig. 1). The frequency of affected cells ranged from 1 to $20 \%$ with a mean of $9 \cdot 3 \%$ inclusions per cell sample. Cells containing abundant parallel tubular arrays and/or with a 'hand mirror' configuration were generally devoid of these inclusions, which were usually to be found in small round cells with a high nucleo-cytoplasmic ratio, occasional strands of rough endoplasmic reticulum. and sparse organelles. The inclusions were frequently located opposite the identation or cleft in the nucleus when this was present. Similar inclusions were also found in occasional control cells. Six of the 14 patients with rheumatoid disease and four of the 12 non-rheumatoid controls were thus affected, with a maximum frequency of two involved cells, and means of $0.86 \%$ and $0.83 \%$ inclusions per cell sample respectively (see Tables 2 and 3 ). There was

Table 1 Chloroquine treated group*

\begin{tabular}{|c|c|c|c|c|}
\hline $\begin{array}{l}\text { Diagnosis } \\
\text { (SCAT) }\end{array}$ & $\begin{array}{l}\text { Duration of } \\
\text { chloroquine } \\
\text { treatment }\end{array}$ & $\begin{array}{l}\text { Concomitamt } \\
\text { drugs }\end{array}$ & $\begin{array}{l}\text { Inclusions } \\
\text { IO() lymphocytes }\end{array}$ & $\begin{array}{l}\text { Inclusions } 200 \\
\text { polymorphonuclear } \\
\text { neutrophils }\end{array}$ \\
\hline $\mathrm{RA}(+\mathrm{ve})$ & 2 days & $\mathrm{N}$ & 15 & () \\
\hline $\mathrm{RA}$ (+ ve) & 3 days & $\mathrm{FL}$ & 1 & () \\
\hline $\mathrm{RA}(+\mathrm{ve})$ & 1 week & N. DEX & 2 & 0 \\
\hline $\mathrm{RA}$ (- ve) & 8 days & IND. DEX & 2 & 0) \\
\hline RA (- ve) & 9 days & BEN, DEX & 3 & 0 \\
\hline SLE & 2 weeks & DEX & 15 & 12 \\
\hline RA (- ve) & 2.5 weeks & FL & 20) & 381 \\
\hline $\mathrm{RA}(+\mathrm{ve})$ & 3 weeks & $\mathrm{FL}$ & 2 & 117 \\
\hline $\mathrm{RA}(+\mathrm{ve})$ & 2 months & PIR & 2 & () \\
\hline $\mathrm{RA}(+\mathrm{ve})$ & 3 months & $\mathrm{FL}$ & 6 & () \\
\hline SLE & 3 months & - & 2 & () \\
\hline RA (- ve) & 4 months & FL. PIR & 12 & () \\
\hline $\mathrm{RA}(-\mathrm{ve})$ & 5 months & $\mathrm{FL}$ & 4 & 0 \\
\hline $\mathrm{RA}(-\mathrm{ve})$ & 7 months & FEN & 23 & 226 \\
\hline SLE & 10 months & - & 10 & 16 \\
\hline RA (+ ve) & 12 months & $\mathrm{N}$ & 2 & () \\
\hline $\mathrm{RA}(+\mathrm{ve})$ & 14 months & N. PRED & 8 & 208 \\
\hline SLE & 14 months & DIC. DEX & 21 & 0 \\
\hline $\mathrm{RA}(-\mathrm{ve})$ & 15 months & $\mathrm{N}$ & 7 & () \\
\hline RA (+ve) & 16 months & IND & 9 & () \\
\hline $\mathrm{RA}(+\mathrm{ve})$ & 18 months & PAN & 8 & 2 \\
\hline $\mathrm{RA}(+\mathrm{ve})$ & 20 months & - & 30 & 48 \\
\hline
\end{tabular}

*Age: range $29-77$ years. mean 51

Key to tables: $A S P=$ Aspirin. $B E N=$ Benorylate. $D E X=$ Dextropropoxyphene. DIC $=$ Diclofenac. $F E N=F e n b u f e n . F L=F l u r b i p r o f e n$. IBU =Ibuprofen. IND=Indomethacin. $\mathrm{MEF}=$ Mefenamic acid. $\mathrm{N}=$ Naproxen. $\mathrm{PAN}=\mathrm{Paracetamol} / \mathrm{codeine}$. PAR=Paracetamol. PIR = Piroxicam. PRED $=$ Prednisolone 


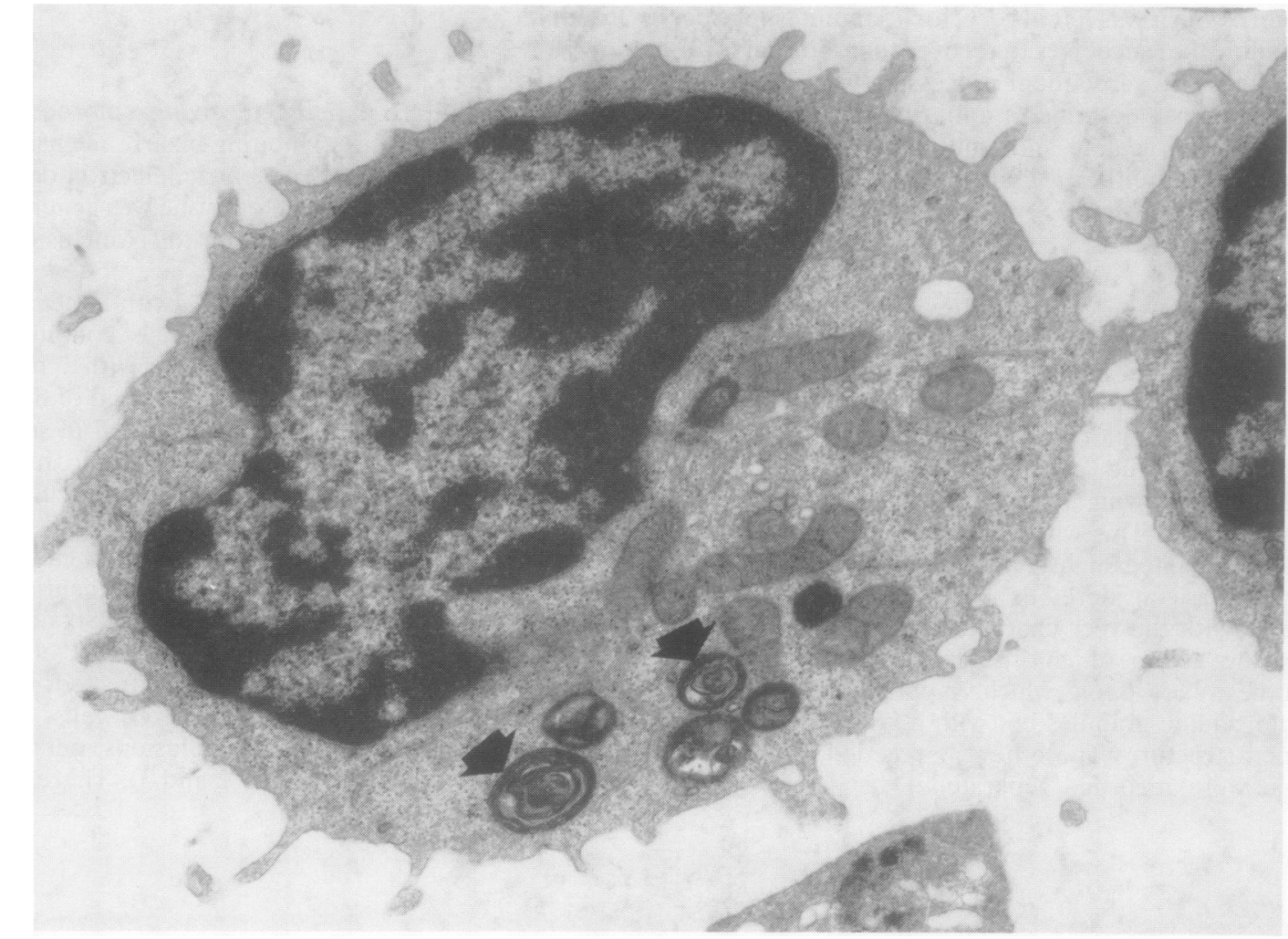

Fig. 1 Lymphocytecontaining lamellarinclusion bodies (arrows) fromapatient (RA) aftersevenmonths' chloroquine therapy. $(E M, \times 22000)$.

a very highly significant difference $(p<0.001)$ between the total number of inclusions in chloroquinetreated patients compared with the two control groups when examined by the Mann-Whitney U test. No significant difference was found between the occurrence of inclusions in the two control populations.

\section{NEUTROPHILS}

The incidence of abnormal inclusions in these cells (Fig. 2) was much lower than that found in the lymphocyte populations, with only eight of the 22 cases showing characteristic lamellar forms in the 200 cell sample (Table 1). There were none present in either control population (Tables 2 and 3). The frequency ranged from 0.5 to $42.5 \%$ affected cells in the 200 cell sample, and the maximum number of abnormal granules found in a single cell section was 14 . Occasional myelin bodies were found in all three groups: $1 \%$ in four chloroquinetreated cases, $0.5 \%$ (three cases) and $1 \%$ ( 2 cases) in five rheumatoid controls, and $0.5 \%$ (three cases) and 3\% (one case) in the non-rheumatoid control sample. There was never more than one myelin body per cell. Analysis of the data by the MannWhitney $U$ test revealed a very significant difference between the number of lamellar inclusions in chloroquine treated patients and non-chloroquine treated rheumatoids $(\mathrm{p}<0.006)$ and also between chloroquine treated patients and non-rheumatoid controls $(p<0.009)$.

\section{Discussion}

Lamellar inclusion bodies, also known as myeloid bodies, have been described in a variety of tissues following chloroquine administration, ${ }^{3}$ but reports of their presence in circulating leucocytes are relatively rare. Fedorko ${ }^{4}$ examined the blood of patients with sarcoidosis who had been treated.with chloroquine phosphate for 2-6 months and found abnormal granules in three out of seven cases. However, no indication of the proportion of cells exhibiting this abnormality was made. 


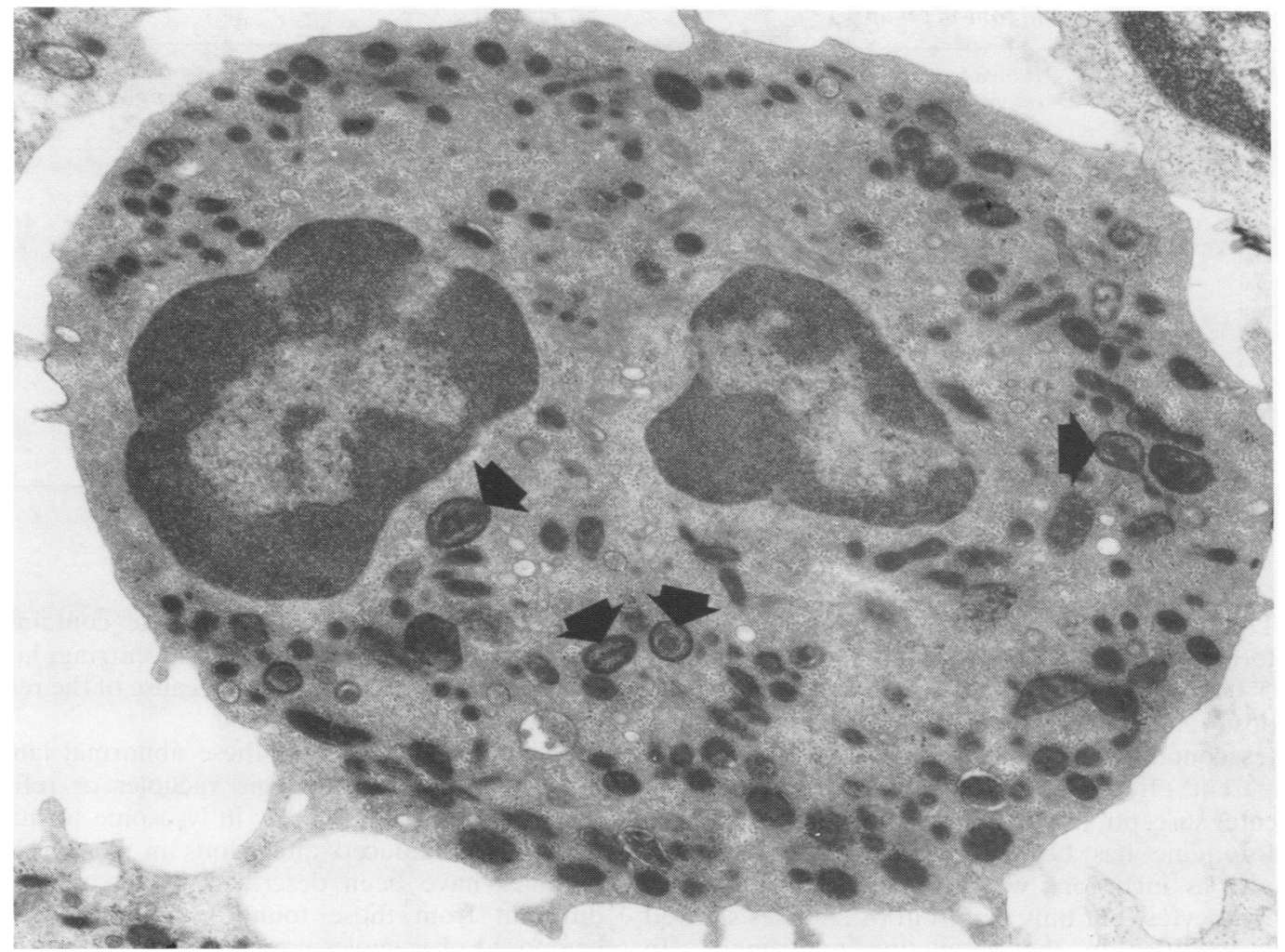

Fig. 2 Abnormalgranules (arrows) in a neutrophil froma patient (RA) aftertwo weeks' chloroquine therapy. (EM, $\times 22000)$.

Table 2 Rheumatoid control group*

\begin{tabular}{|c|c|c|c|c|}
\hline $\begin{array}{l}\text { Diagnosis } \\
\text { (SCAT) }\end{array}$ & $\begin{array}{l}\text { Duration of } \\
\text { chloroquine } \\
\text { treatment }\end{array}$ & $\begin{array}{l}\text { Concomitant } \\
\text { drugs }\end{array}$ & $\begin{array}{l}\text { Inclusions/ } \\
100 \text { lymphocytes }\end{array}$ & $\begin{array}{l}\text { Inclusions } / 200 \\
\text { polymorphonuclear } \\
\text { neutrophils }\end{array}$ \\
\hline RA (- ve) & - & IBU & 3 & 0 \\
\hline RA (- ve) & - & FL & 0 & 0 \\
\hline RA (+ ve) & - & $\mathrm{N}, \mathrm{MEF}$ & 1 & 0 \\
\hline RA (+ ve) & - & PAR & 5 & 0 \\
\hline RA (- ve) & - & DIC, PAR & 0 & 0 \\
\hline RA (- ve) & - & ASP & 0 & 0 \\
\hline RA $(+v e)$ & - & $\mathrm{N}$ & 1 & 0 \\
\hline RA (+ ve) & - & $\mathbf{N}$ & 0 & 0 \\
\hline RA (+ ve) & - & FL & 1 & 0 \\
\hline $\mathrm{RA}(+\mathrm{ve})$ & - & ASP & 0 & 0 \\
\hline $\mathrm{RA}(+\mathrm{ve})$ & - & - & 0 & 0 \\
\hline RA $(+v e)$ & - & $\mathbf{N}$ & 1 & 0 \\
\hline RA (+ ve) & - & FL & 0 & 0 \\
\hline $\mathrm{RA}(+\mathrm{ve})$ & - & IND & 0 & 0 \\
\hline
\end{tabular}

*Age: range 32-79 years, mean 58.

For key to abbreviations see Table 1. 
Table 3 Non-rheumatoid control group*

\begin{tabular}{lllll}
\hline Diagnosis & $\begin{array}{l}\text { Duration of } \\
\text { chloroquine } \\
\text { treatment }\end{array}$ & $\begin{array}{l}\text { Concomitant } \\
\text { drugs }\end{array}$ & $\begin{array}{l}\text { Inclusions/ } \\
\text { I00 lymphocytes }\end{array}$ & $\begin{array}{l}\text { Inclusions/200 } \\
\text { polymorphonuclear } \\
\text { neutrophils }\end{array}$ \\
\hline Cardiac & - & None & 0 & 0 \\
Cardiac & - & None & 0 & 0 \\
Cardiac & - & None & 2 & 0 \\
Normal & - & None & 0 & 0 \\
Normal & - & None & 3 & 0 \\
Normal & - & None & 0 & 0 \\
Normal & - & None & 0 & 0 \\
Normal & - & None & 2 & 0 \\
Normal & - & None & 0 & 0 \\
Normal & - & None & 3 & 0 \\
Normal & - & None & 0 & 0 \\
Normal & None & 0 & 0 \\
\hline
\end{tabular}

*Age: range 23-59 years, mean 45 .

During an in vitro investigation on the effect of chloroquine on leucocytes ${ }^{1}$ we found that incubation in $5-0.05 \mu \mathrm{g} / \mathrm{ml}$ chloroquine for four hours produced a dose-related increase in the number of lymphocytes containing autophagosomes while having no apparent effect on leucocyte ultrastructure. The greater susceptibility of lymphocytes to the action of chloroquine has been confirmed in this in vivo study, as inclusions were found in every case in lymphocytes, but only eight out of 22 cases showed abnormalities in the circulating neutrophils. In general it was found that high numbers of inclusions in the lymphocyte population were associated with affected neutrophils. Similar inclusions were also found in control lymphocytes, though the number of affected cells was much lower. There are several possible explanations for this:

(1) Chloroquine increases the incidence of a natural phenomenon (e.g., the existence of myelin bodies) which is found in normal circulating cells.

(2) The myelin bodies found in normal lymphocytes are artefacts produced by glutaraldehyde fixation, which permits the leaching out of lipid from cytomembranes, allowing it to mix with an aqueous environment and produce lamellar formations; these are subsequently fixed by the osmium tetroxide used at a later stage of processing. ${ }^{5}$ It is possible that chloroquine, which is known to concentrate in lysosomes, ${ }^{6}$ renders lipid more susceptible to such a leaching out process by altering the physical properties of lysosomal membranes. ${ }^{3}$

(3) Circulating basophils contain numerous large granules which often form lamellar or membranous inclusions very similar to myelin bodies. It is possible that ultrathin sectioning may itself produce an image of a cell showing the nucleus and part of such a granule, which would then be virtually indistinguishable from a lymphocyte containing a myelin body. The chances of this occurring, however, are considered to be small because of the relative paucity of basophils in blood.

It is not clear whether these abnormal lamellar bodies represent autophagic vacuoles or reflect a developmental abnormality in lysosome formation. Chloroquine-induced alterations in rat myelocyte granules have been described ${ }^{7}$ which were quite different from those found in our study, being composed of vacuoles containing ribosomes, membranous structures, and one or more osmiophilic granules suggestive of an autophagic process. Our in vitro study ${ }^{1}$ also implied the activation of autophagy by chloroquine, with large vacuoles containing electron-dense whorls, lamellae and electron-dense debris being found in lymphocytes after four hours' incubation. It is possible that the granules found in the cells of our patients represent a later stage in the autophagic process, when residual bodies containing condensed breakdown products are present.

The existence of such electron-dense membranous inclusions is a feature of many tissues following chloroquine treatment and suggests impaired digestion by lysosomal enzymes. It has been postulated that chloroquine initially labilises lysosomal membranes, releasing digestive enzymes and initiating autophagy, while multiple treatments induce membrane stability, impeding the entry of enzymes into lysosomes to produce an accumulation of undegraded sequestered material. ${ }^{8}$ Later workers have, however, shown that chloroquine can inhibit directly the activity of enzymes such as cathepsin $B_{1}{ }^{9}$ and phospholipase $\mathrm{A}_{2}{ }^{10}$ and this may account for the resemblance of the vacuolar contents to undegraded phospholipid.

It seems likely that these abnormal lysosomes 
may affect the normal functions of lymphocytes and thus account for some of the reported immunosuppressive effects of chloroquine. ${ }^{11} 12$ The results of any decrease in lysosomal enzyme activity of neutrophils may be that the amount of tissue damage associated with granule release and phagocytosis is diminished. This could provide a basis for the anti-inflammatory properties of the drug. A detailed discussion of the reported effects of chloroquine on lymphocyte and neutrophil function has been presented elsewhere.'

There was no apparent correlation between the number of lamellar inclusions in either lymphocytes or neutrophils and the duration of chloroquine treatment or the serological status of the patient. The presence of lamellar inclusion bodies as soon as two days after the initiation of chloroquine therapy contrasts with the finding that clinical improvement is seldom observed before four weeks and that it takes three to six months before maximal benefits are achieved. ${ }^{13}$ Because almost all the patients receiving chloroquine were also on non-steroidal anti-inflammatory drugs, it was not possible to correlate the presence of a high number of lamellar inclusions with an improvement (or otherwise) in the clinical condition.

Should further studies demonstrate a link between the presence of lamellar bodies in neutrophils and clinical improvement, then the examination of circulating cells would provide a direct and objective way of monitoring the efficacy of the drug with respect to any particular patient.

We wish to thank patients and staff of Hope Hospital, Salford, for kindly donating samples of blood, and the Department of Medical
Computation. University of Manchester for statistical assistance and advice. Dr Jones was supported by grants from the Dr Hadwen Trust for Humane Research and the North Western Regional Health Authority, to whom we are most grateful.

\section{References}

1 Jones C J P. Jayson M I V. Chloroquine: its effect on leucocyte auto- and heterophagocytosis. Ann Rheum Dis 1984; 43: 205-12.

2 Jones C J P. Morris K J. Jayson M I V. Prednisolone inhibits phagocytosis by polymorphonuclear leucocyes via steroid receptor mediated events. Ann Rheum Dis 1983; 42: 56-62.

3 Read W K. Bay W W. Basic cellular lesions in chloroquine toxicity. Lab Invest 1971: 24: 246-59.

4 Fedorko M. Effect of chloroquine on morphology of cytoplasmic granules in maturing human leukocytes. An ultrastructural study. J Clin Invest 1967; 46: 1932-42.

5 Ghadially F N. Ultrastructural pathology of the cell. London: Butterworths, 1978.

6 Allison A C. Young M R. Uptake of dyes and drugs by living cells in culture. Life $S_{c i}$ 1964: 3: 1407-14.

7 Fedorko M. Effect of chloroquine on morphology of leukocytes and pancreatic exocrine cells from the rat. Lab Invest 1968; 18: 27-37.

8 Abraham R. Hendy R. Grasso P. Formation of myeloid bodies in rat liver lysosomes after chloroquine administration. Exp Mol Pathol 1968; 9: 212-29.

9 Wibo M. Poole B. Protein degradation in cultured cells. (2) The uptake of chloroquine by rat fibroblasts and the inhibition of cellular protein degradation and cathepsin $B_{1}$. J Cell Biol 1974: 63: $430-40$.

10 Matsuzawa Y. Hostetler K Y. Inhibition of lysosomal phospholipase $A$ and phospholipase $C$ by chloroquine and 4.4'bis(diethylaminoethoxy) alpha. beta-diethyldiphenylethane. $J$ Biol Chem 1980; 255: 5190-4.

11 Panayi G S. Neill W A. Duthic J J R. McCormick J N. Action of chloroquine phosphate in rheumatoid arthritis. I. Immunosuppressive effect. Ann Rheum Dis 1973; 32: 316-8.

12 Trist D G. Weatherall M. Inhibition of lymphocyte transformation by mepacrine and chloroquine. J Pharm Pharmacol 1981: 33: 434-8.

13 Zvaifler N J. Antimalarial treatment of rheumatoid arthritis. Med Clin North Am 1968: 52: 759-64. 